\title{
Not fair but acceptable... for us! Group membership influences the tradeoff between equality and utility in a Third Party Ultimatum Game
}

\author{
Marco Biella*, Simona Sacchi \\ Department of Psychology, University of Milano-Bicocca, Italy
}

\section{A R T I C L E I N F O}

Handling editor: Shaul Shalvi

Keywords:

Ultimatum game

Inequality

Group membership

Economic decision-making

Ingroup bias

\begin{abstract}
A B S T R A C T
A substantial body of literature on economic games (e.g., the Ultimatum Game) has consistently demonstrated that individuals strongly reject unfairness even at the price of personal utility. In four experiments we investigated the influence of social categorization and membership on economic decision-making and inequality aversion. Specifically, we used a modified version of the Third Party Ultimatum Game, in which participants played the role of responder and were instructed to make decisions for themselves or another individual (i.e. the receiver of the economic offer) who was an ingroup or outgroup member. Experiments $1-2(N=173)$ showed that the participants were more likely to accept unequal-advantageous offers when the receivers were ingroup rather than outgroup members. Experiment $3(N=121)$ supported previous findings and suggested the intervening role played by perceived intergroup competition. Experiment $4(N=61)$ explored the effect boundary conditions. Findings revealed that, even when responder's utility is linked to the receiver's utility, the receiver's membership exerted its influence when the responders were highly identified with the ingroup. A final smallscale meta-analysis confirmed the robustness of our findings. Taken together, these results integrate research on economic decision-making and intergroup bias and suggest that the utility target's membership can resolve the conflict between inequality aversion and utility maximization.
\end{abstract}

Social and economic disparities represent key challenges of our time (e.g., the World Economic Forum). According to current economic analyses, the richest $1 \%$ of the world owns more than half of the globe's total wealth; moreover, in developed and developing countries, the poorest part of the population controls $<10 \%$ of its wealth (Oxfam, 2015). One point in this public debate is whether and to what extent these disparities are exclusively a result of the system structure rather than individuals' misbehavior, including the tendency to favor one's own group, the promotion of lobbying campaigns to protect and enhance one's own interests and the disregard of social inequality. The dispute between self-interest motive and fair conduct in economic decision-making and behavior has long been investigated by disciplines such as economics, psychology, sociology and social science in general. Specifically, a substantial body of psychological literature on economic games has explored whether and under what conditions individuals are likely to reject rather than accept unfairness, particularly when a rejection entails costs in terms of personal utility (Güth, Schmittberger, \& Schwarze, 1982). The present work aimed to extend prior research on the conflict between equality and utility preferences in decisionmaking. As most decisions (and economic decisions in particular) involve social groups, this research investigated the influence of group membership and social categorization on individual economic reasoning. Moreover, the experimental paradigm devised for the present studies (i.e., Third Party Ultimatum Game, TPUG) enabled an analysis of the reactions to inequality, disentangling its effect from the influence of personal utility deviation.

\section{Inequality and decision-making}

Fairness and social equality are pillars of interpersonal interactions and human sociality. They appear early in humans (Fehr, Bernhard, \& Rockenbach, 2008; Warneken \& Tomasello, 2006), and they are shared with other primates (Brosnan \& de Waal, 2003; Brosnan, Schiff, \& de Waal, 2005). Moreover, they are applied spontaneously: as the evolutionary perspective suggests, fairness is one of the natural moral instincts with which human beings are endowed (Alexander, 1987; Boehm, 1999; Darwin, 1871) as it maximizes individual survival by providing benefits for the group.

Given their centrality in an individual's psychological life, fairness and equality are likely to tailor cognitive processes, judgments and choices, thus leading human decision-making (Civai, 2013; Fehr \& Schmidt, 1999; Messick \& Schell, 1992). A considerable number of

\footnotetext{
* Corresponding author at: Department of Psychology, University of Milano-Bicocca, P.zza dell'Ateneo Nuovo 1, 20126, Milan, Italy.

E-mail address: m.biella6@campus.unimib.it (M. Biella).
} 
studies have investigated the reactions to unfairness and inequality, as well as positive (vs negative) utility (e.g., Cialdini \& Goldstein, 2004; Falk \& Fischbacher, 2006; Friedman, 1953; Messick \& Thorngate, 1967; Rabin, 1993). For example, previous research has highlighted that individuals may generally show inequality aversion (Bolton, 1991; Bolton \& Ockenfels, 2000; Fehr \& Schmidt, 1999) to the point of sacrificing personal resources and payoff to move in the direction of a fair outcome (Fehr \& Schmidt, 1999). Moreover, psychological literature on the use of heuristics in economics reasoning has indicated that decision-makers are likely to use criteria of equality (Messick \& Schell, 1992), procedural justice (Schroeder, Steel, Woodel, \& Bembenek, 2003), and social norms (Civai, Rumiati, \& Rustichini, 2013) to solve problems of resource allocation. In this vein, Messick and Schell (1992) reported that individuals heuristically use equality as a main principle during their reasoning, particularly when no other criterion appears to be applicable.

A clear example of a situation in which statements of classic theories on gain maximization are violated is the Ultimatum Game (UG; Güth et al., 1982). The UG is an experimental game in which two participants split resources in a strategic manner. The first participant, referred to as the proposer, is endowed with the resources and decides how to split them; the second participant, referred to as the receiver or the responder, decides to accept or refuse the splitting proposal. If the responder accepts, the resources are divided as proposed; if s/he refuses, both participants gain nothing. Standard economic theory states that the proposer should act egoistically by splitting resources (e.g., \$10) as unequally as possible in his/her favor (e.g., proposer: $\$ 9$, receiver: $\$ 1$ ) and the receiver should accept every possible proposal because a rejection indicates that his/her utility goes to 0 and is no longer maximized ( $\$ 1$ is more than $\$ 0$ ). However, although equal splits and rejection to unequal offers are considered a contradiction of the standard economic theory, there have been many empirical demonstrations of these violations (Güth et al., 1982).

In addition to self-interest and personal gain maximization, (un) fairness appears to play an important role in economic behavior. Unfairness related to unequal splits in the UG may induce negative emotions (Civai, Corradi DellAcqua, Gamer, \& Rumiati, 2010) and negative reciprocity (Rabin, 1993), which, in turn, drive rejection behavior to restore relative gain equality (a null gain for both participants). Neuroscience and physiological evidence have supported this perspective (Sanfey, Rilling, Aronson, Nystrom, \& Cohen, 2003). The idea that rejections may be caused by a negative affective state is sustained by the correlation between the rejection rate and increased emotional arousal, as indexed by skin conductance (van't Wout, Kahn, Sanfey, \& Aleman, 2006). Moreover, unequal offer rejections are related to greater activation of the anterior insula, a brain region previously associated with negative emotions such as anger and disgust (Sanfey et al., 2003).

However, as noted by Civai et al. (2013), the classic UG paradigm is unlikely to disentangle a genuine reaction toward inequality and a mere safeguard of self-interests because of the overlap between the role of the decision-maker and the role of the utility receiver (Güth, Schmidt, \& Sutter, 2007). As the responder plays both roles at the same time, it is difficult to distinguish which motivation is responsible for the final behavior. This severe limitation may be overcome using a Third Party Ultimatum Game (Civai et al., 2010; Civai, Crescentini, Rustichini, \& Rumiati, 2012). In this variation of the original paradigm, the roles of the decision-maker and utility receiver do not overlap because they are played by different agents. In general, the first is the experimental subject who makes decisions and evaluates proposals, and the second is a third party who only receives utility generated by the former's decisions. Thus, as the decision maker does not receive the utility produced by his/her decisions, this modification enable an unambiguous analysis of the influence of inequality aversion, thus ruling out potential selfinterest explanations.

\section{Economic decision, inequality aversion and ingroup bias}

Most of the previously described research on unfairness rejection assumed only an individual or an interpersonal perspective, and limited studies have included the presence of a third party to manipulate selfinvolvement (Civai et al., 2010; Civai et al., 2013). Thus, the social connotations of the agents have been largely disregarded. However, within this framework, an interesting line of research started to explore the influence of the intergroup bias on the economic decision-making.

Intergroup bias is a general tendency to favor an ingroup member and/or derogate an outgroup member (for a review, refer to Brown, 2000; Hewstone, Rubin, \& Willis, 2002; Tajfel, Billig, Bundy, \& Flament, 1971; Tajfel \& Turner, 1979; Turner \& Reynolds, 2001). This phenomenon lies at the core of social psychology and shapes attitudes and behaviors in every domain. Previous research related to the tradeoff between utility maximization and inequality aversion has suggested the role of group membership and group affiliation in economic behavior (refer also to, Abbink, Brandts, Herrmann, \& Orzen, 2012; De Dreu et al., 2004; Yamagishi \& Mifune, 2015). As remarkable examples, studies on parochial altruism and third party punishment (Bernhard, Fischbacher, \& Fehr, 2006; Henrich et al., 2006) have suggested that individuals tend to favor the same ethnic, racial, language or broad social group members to promote social group positioning; moreover, they are willing to administer costly punishment to unequal behavior as a function of violators' group membership.

According to this perspective, Kubota, Li, Bar-David, Banaji, and Phelps (2013) obtained striking findings of intergroup discrimination in the UG. In their work, White participants holding a negative implicit attitude toward Black Americans accepted more offers and lower offer amounts from White proposers than from Black proposers. Moreover, they showed that the same offer was considered less equitable when it originated from a Black individual rather than a White individual. In the same vein, Mendoza, Lane, and Amodio (2014) determined that receivers were more likely to reject unfair proposals when they were offered by ingroup rather than outgroup proposers. This counterintuitive phenomenon was explained in terms of greater severity toward ingroup members who violate the group-based norms of reciprocity and fairness.

In summary, this line of research has consistently noted that economic behavior and individuals' reactions to inequality were influenced and moderated by social factors, such as group membership. In the present work, we investigated social variables (i.e. social membership) likely to influence inequality rejection in economic decision-making when the decision-maker and the utility receiver did not coincide.

\section{The present research}

Prior studies on the UG explored the role of membership; however, it left several important questions unanswered. Previous research has typically analyzed the acceptance of equal offers as an application of the fairness norm (Messick \& Schell, 1992) and the rejections of unequal-disadvantageous offers as the result of negative emotions (Sanfey et al., 2003) or cognitive heuristics (Civai et al., 2013). However, the literature has largely neglected a systematic investigation of the behavioral responses in cases of unequal-advantageous offers (offers that are unequal but advantageous for the receiver; e.g., proposer: $\$ 1$, receiver: $\$ 9$,) as well as the role of social factors in this process (e.g., Civai et al., 2013; Smith \& Henry, 1996).

To fill this gap, the present research aimed to explore the reaction to equal, unequal-disadvantageous and unequal-advantageous offers when the receiver is an ingroup rather than an outgroup member. For this purpose, we adopted the TPUG paradigm to avoid confounding between inequality aversion and personal gain maximization (Civai et al., 2013).

Specifically, based on the assumption that individuals tend to favor their own ingroup with regards to the outgroup (Tajfel \& Turner, 1979; 
for a review, refer to Hewstone et al., 2002) and are prone to consider the ingroup as an extension of the Self (Aron \& Aron, 1997; Tropp \& Wright, 2001), we hypothesize that when the third-party receivers are ingroup members, the responders are likely to accept unequal-advantageous offers as in the classic UG when they directly receive the utility. In this vein, literature on negotiation (Tyler \& Hastie, 1991) suggested that the individuals' tendency to overestimate their qualities would lead to find justice in unequal distributions that favor their own position. In contrast and different from the standard UG, we hypothesize that when the receivers are outgroup members, the responders would be more prone to reject unequal-advantageous offers, thus promoting a firmer application of the equality norm. This rejection may be considered an expression of intergroup bias and motive to reduce utility and benefit for the outgroup.

We tested these hypotheses through three experimental studies in which we adopted the TPUG. We manipulated the receiver membership (ingroup vs outgroup) using bogus feedback on a fake personality test and the t-shirt color (for example, refer to Gaertner, Mann, Murrell, \& Dovidio, 1989; Homan, van Knippenberg, Van Kleef, \& De Dreu, 2007; Pickett, Silver, \& Brewer, 2002) and we tested the effect of this manipulation on an individual's decision-making. Moreover, in the third study, we explicitly investigated the moderator role of perceived intergroup competition. Finally, in the fourth study, we bounded the decision-maker's utility to the receiver's gain to explore the effect robustness. Finally, a small-scale meta-analysis of the four studies was conducted. Sample size was determined before any data analysis. All measures, manipulations, and participant exclusions in the studies are disclosed in the results section, as well as the method of determining the final sample size. The three studies were conducted in accordance with the ethical standards described in the 1964 Declaration of Helsinki and fulfilled the ethical standard procedure recommended by the Italian Association of Psychology (AIP).

\section{Experiment 1}

The main purpose of Experiment 1 is to provide the first experimental support for our hypotheses. Experiment 1 aimed to understand how the group membership of the utility receiver influences the decision outcome. For this purpose, the participants were asked to play in a TPUG (decision-makers do not receive the utility of their decision) that was compared with a standard UG as the control condition (participants receive the utility of their decision); this approach enabled us to disentangle the effect of inequality aversion and self-interest as drivers of economic decision-making. Moreover, we manipulated the interaction partner's social membership to determinate whether social information impacted inequality aversion.

\subsection{Participants}

An a priori power analysis was conducted for sample size estimation (using GPower 3.1; Faul, Erdfelder, Lang, \& Buchner, 2007). With alpha $=0.05$ and power $=0.80$, the projected sample size needed to detect a medium to large effect size $\left(f^{2}=0.15\right.$, Cohen, 1988) is approximately $N=93$ for an interaction between-within subjects mixed ANOVA with 3 condition and 3 measurements. We recruited a slightly larger sample in order to deal with possible missing data. Thus, we advertised the study and enrolled 96 participants who took part in the study in exchange for course. The sample included 71 females $\left(M_{\mathrm{age}}=23.85 ; S D_{\mathrm{age}}=4.59\right)$. All participants were Italian citizens.

\subsection{Materials and procedure}

Seven days before the laboratory experiments, all participants were administered an online questionnaire on personal characteristics, such as aesthetic preferences and behavioral tendencies. The questionnaire was a bogus personality test with the sole purpose to justify the division of participants in two teams, thus introducing our group manipulation.

After 7 days, each participant was called by the researcher for the laboratory session. Upon their arrival at the laboratory, the participants read and signed the informed consent. It was subsequently explained that the personality test was devised to assign them to one of two teams, the Blue team or the Orange team, to maximize similarity within each team and minimize it between teams. We subsequently asked them to wear a shirt of the color of their team to strengthen the membership manipulation (e.g. Gaertner et al., 1989). We did not use other social categorization criteria (e.g. ethnic) to limit the influence of a-priori beliefs or stereotypes on salient social groups on the adopted fairness norm. Indeed, the formation of ad-hoc and unknown groups would make more probable the use of the equality rule as benchmark (i.e., equal resources distribution among interaction partners) than other fairness rules as equity or need (Mannix, Neale, \& Northcraft, 1995). Actually, the participants were randomly assigned to one of the two teams.

Once assigned to the team membership, the participants were seated in front of a pc and participated as a respondent in one of the three different versions of the UG. We used a Third-Party version of the UG (TPUG; Civai et al., 2010), in which the participants played several rounds of the game, always in the role of the responder.

In two experimental conditions, the participants played the role of the decision-makers (responders) and were asked to accept or reject the proposer's offers on the behalf of the receiver, who was the third party. The participants were informed that two other players were recruited: the first participant played the role of the proposer and had no membership because s/he was recruited at that moment and thus did not complete the questionnaire; the second participant played the role of the receiver and had a specific membership, Blue or Orange. The partners were fictitiously located in two different rooms, and the participants did not receive additional clues on their identity. The participants were led to believe that the proposer and the receiver would receive their part of the split at every accepted offer whereas the responders did not receive utility.

After the general instruction, the membership manipulation was introduced. Thus, in the ingroup experimental condition, the third party (the receiver) was presented as an ingroup member (i.e., the same group - Orange or Blue - of the responder); in the outgroup experimental condition, the third party was presented as an outgroup member. Such a manipulation was enhanced by coloring (in blue or orange) the label "receiver" on the screen every time the offer was presented (see Fig. 1). The proposer was presented as belonging to none of the groups across all conditions and the label "proposer" was always in black. In a third control condition, the participants were presented with the standard version of the UG, in which they played the roles of the decision-maker and final receiver of the utility.

The procedure did not require interaction between players. There were no other participants, and the different offers were randomly presented by an Inquisit script. The Inquisit script presented participants in the control $(N=30)$, ingroup $(N=33)$ and outgroup $(N=33)$ conditions with the same set of division offers. The proposal was changed by manipulating different ratios of resources for the proposer and the receiver. The possible ratios covered the entire range of possible splits of 10 euros $(1: 9 ; 2: 8 ; 3: 7 ; 4: 6 ; 5: 5 ; 6: 4 ; 7: 3 ; 8: 2 ; 9: 1)$ from the least to the most advantageous for the receiver. The first four levels correspond to unequal-disadvantageous offers for the receiver, the last four levels correspond to unequal-advantageous offers and (5:5) is an equal offer. Every proposal was presented three times in random order for a total of 27 trials. The participants responded by pressing the A key (accept) or the R key (reject) on the keyboard. After every accepted trial, the total amount gained by the receiver, which was constantly visible on the pc screen, was incremented of an amount equals to the part of the split destined to the receiver, whereas after a rejected trial, the total amount did not increase. The participant's response and the reaction time required to make a decision were recorded. 


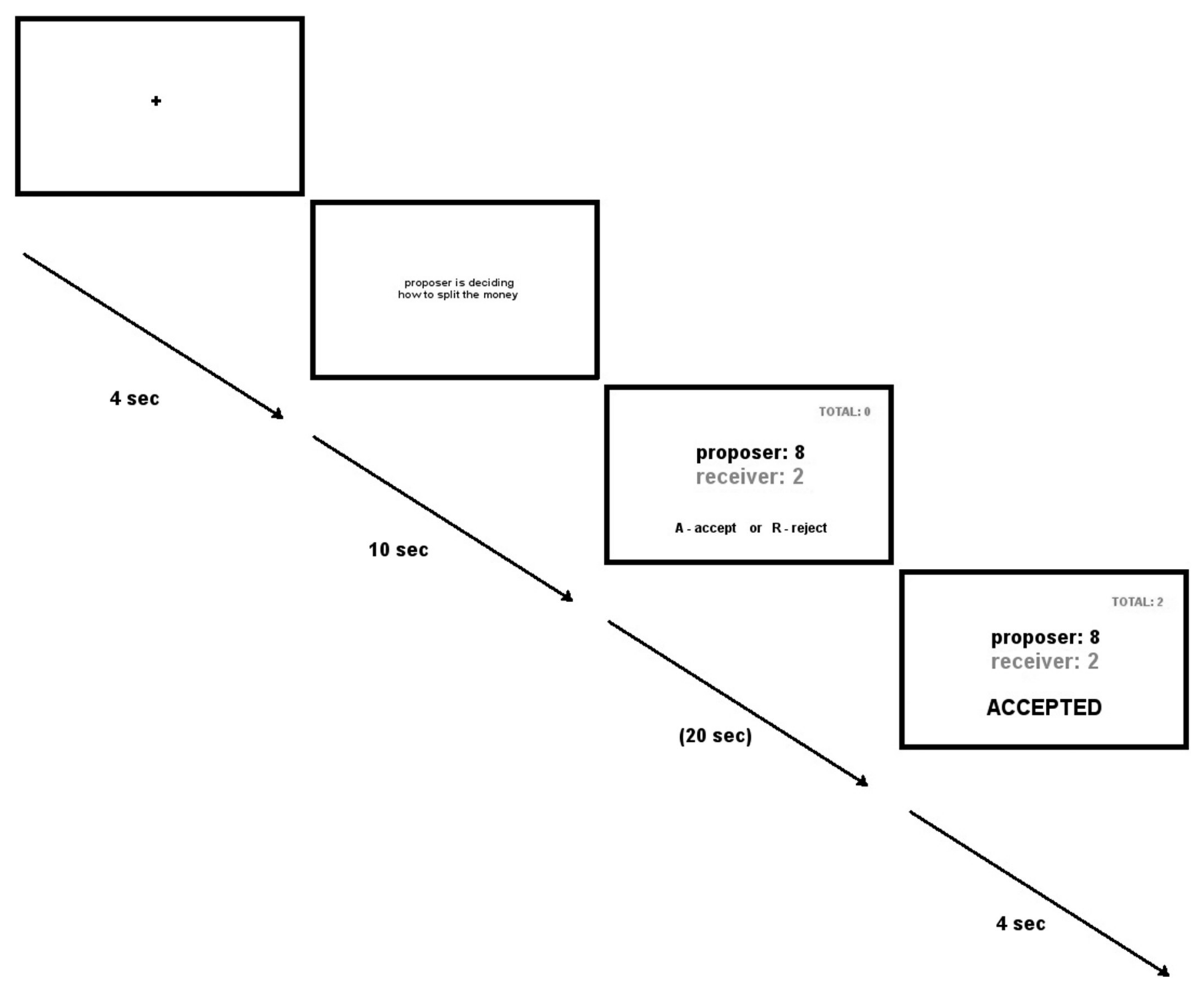

Fig. 1. Schematic drawing of the trial flow (in Italian in the original version).

Following previous studies on the TPUG, we adopted a repeated game that manipulated the offer levels within-participants (Civai et al., 2012, 2013). During the game, the identities of the proposer and receiver did not change. To limit reputation biases (Bromley, 1993; Tetlock \& Manstead, 1985), the participants were told that the other player and the experimenter would not discover their trial-by-trial choices.

At the end of the UG, the participants were properly debriefed.

\section{Results}

The study employed a 3 (offer: unequal-disadvantageous, equal, unequal-advantageous) $\times 3$ (condition: control, ingroup, outgroup) $\times 2$ (team: blue vs orange) experimental design with the first factor varied within participants and the other two factors between participants. Our main dependent variables were the acceptance index (the percentage of accepted offers) and the reaction times to make the decision.

\subsection{Preliminary analyses}

We preliminarily conducted a 2 (team: Blue vs Orange) $\times 3$ (condition: control, ingroup, outgroup) $\times 3$ (offer level: unequal- disadvantageous, equal, unequal-advantageous) ANOVA on the acceptance index to rule out whether the participants' behavior was driven by the team to which they were assigned. This analysis indicated a marginally significant main effect of team, $F(1,90)=3.60, p=.061$, $\eta^{2}=0.038$, and no two- or three-way interaction effects involving team, $F s<0.44$, $p s>.25, \eta_{\mathrm{p}}{ }^{2}<0.01$. The Blue team $(M=0.72$, $S D=0.33)$ accepted marginally more $(M=0.67, S D=0.38)$ offers than the Orange team, regardless of condition and offer level. The same ANOVA on the reaction times indicated no main effect of team, $F(1$, $90)=0.42, p=.52, \eta^{2}=0.005$, or two- or three- way interaction effects involving team $F s<3.66$, $p s>.25, \eta_{\mathrm{p}}{ }^{2}<0.04$.

Because the ANOVAs did not indicate any interaction effects with our crucial variables, we collapsed the data across membership. Thus, the following analyses do not consider this factor.

\subsection{Main analyses}

A 3 (condition: control, ingroup, outgroup) $\times 3$ (offer level: unequal-disadvantageous, equal, unequal-advantageous) ANOVA, with the first factor manipulated between subjects and the second factor manipulated within subjects, was conducted on the acceptance index.

This analysis revealed no significant effect of condition, $F(2$, $93)=0.77, p=.47, \eta^{2}=0.02$, and a significant main effect of offer 
Table 1

Acceptance Index in the different experimental condition for different offer levels. Experiment 1.

\begin{tabular}{llll}
\hline & Unequal-disadvantageous & Equal & Unequal-advantageous \\
\hline Control & $0.30(0.23)$ & $0.97(0.18)$ & $0.80(0.29)$ \\
Ingroup & $0.31(0.23)$ & $0.95(0.19)$ & $0.89(0.20)$ \\
Outgroup & $0.40(0.29)$ & $0.96(0.16)$ & $0.67(0.32)$ \\
Total & $0.34(0.26)$ & $0.96(0.18)$ & $0.79(0.28)$
\end{tabular}

level, $F(1,93)=169.35, p<.001, \eta^{2}=0.65$. Therefore, as the posthoc comparisons showed, the equal offers $(M=0.96, S D=0.18)$ were accepted more frequently than unequal-disadvantageous $(M=0.34$, $S D=0.26)$ and unequal-advantageous offers $(M=0.79, S D=0.28)$, $p<.001$ [ $d=1.98$; CI: 1.63, 2.32], and the latter were more accepted than the unequal-disadvantageous counterpart, $p<.001[d=1.11$; CI: $0.85,1.36]$. These results are in contrast with normative standard economic theory and consistent with the existing experimental literature on the UG.

Moreover, in line with the crucial hypothesis, the analysis indicated a significant interaction effect between offer level and condition, $F(2$, $93)=4.03, p=.02, \eta^{2}=0.080$. This interaction was significant even re-including in the ANOVA the team to which the participant was assigned, $F(2,90)=3.97, p=.02, \eta^{2}=0.08$. As Table 1 shows, we found that, for unequal-advantageous offers, participants in the outgroup condition $(M=0.67, S D=0.32)$ are less likely to accept the offer than the participants in ingroup condition $(M=0.89, S D=0.20), p<.001$ $[d=0.85$; CI: $0.35,1.36]$, and marginally less likely than the participants in control condition $(M=0.80, S D=0.29), p=.06[d=0.42$; CI: $-0.07,0.91]$. Moreover, the analysis did not yield any difference between the control and ingroup condition, $p=.18[d=0.39$; CI: $-0.11,0.89]$. These findings suggest that when the relative utility is maximized in favor of the Self or of an ingroup member, individuals are more prone to accept unequal offers; on the contrary, when the relative utility is in favor of an outgroup member, the decision-maker tends to reject unequal options. Further comparisons showed no differences between groups for the unequal-disadvantageous offers and equal offers. Post-hoc for the unequal-disadvantageous (control: $M=0.30$, $S D=0.23 ;$ ingroup: $M=0.31, S D=0.23$; outgroup: $M=0.40$, $S D=0.29$ ) and equal (control: $M=0.97, S D=0.18$; ingroup: $M=0.95, S D=0.19$; outgroup: $M=0.96, S D=0.16$ ) offers did not reach statistical significance, $p s>.11$ and $p s>.70$ respectively.

In addition, as the division options may be considered along a continuum, we analyzed the data using a generalized linear mixed model. The condition was introduced as a categorical variable using the ingroup condition as a reference group, the offer level was introduced as a continuous predictor ranging from 1 (the most disadvantageous for the responder) to 9 (the most advantageous for the responder) and the dependent variable was the decision outcome where accepted offers were coded as 1 and rejected offers were coded as 0 . Given the dichotomous nature of the dependent variable we employed a logistic link function.

As expected and consistent with the previous analysis, we found a main effect of offer level ( $\mathrm{B}=1.27, \mathrm{SE}=0.21, z=6.03, p<.001)$, indicating that the participants are more likely to reject the unequaldisadvantageous offers and to accept unequal-advantageous ones.

Moreover, in line with our main hypothesis, the interaction between the offer level and condition was significant $(\mathrm{B}=-0.62$, $\mathrm{SE}=0.28$, $z=-2.24, p=.03$ ) when we compared the ingroup and outgroup conditions indicating that, as the offer level rises (i.e., when the division options became unequal-advantageous), the participants in the outgroup condition tended to reject more offers than the participants in ingroup condition.

Moreover, the analysis did not yield a significant interaction between the offer level and condition $(\mathrm{B}=0.05, \mathrm{SE}=1.21, z=0.04$, $p=.96)$ when we compared the ingroup and control conditions indicating that the decision outcome of the participants in the control condition was not different from the outcome of the participant in the ingroup condition.

These results are the first experimental evidence in support of our hypothesis. Since the participants in the ingroup and control conditions behaved in the same way in the case of unequal-advantageous offers (at least in such a way that is statistically indistinct), we can conclude that the decision outcome is the same for those who are deciding for themselves and those who are deciding on behalf of an ingroup member. Moreover, in the case of the unequal-advantageous offers, only the participants in the outgroup condition reject such unequal options.

\subsection{Reaction times}

Finally, we conducted the same 3 (condition: control, ingroup, outgroup) $\times 3$ (offer level: unequal-disadvantageous, equal, unequaladvantageous) ANOVA on the reaction times. In this case, we found no main effect of the experimental condition or an interaction effect between the condition and offer level, $p s>.19$. However, the analysis identified a main effect of the offer level, $F(1,93)=30.51, p<.001$, $\eta^{2}=0.25$. The post-hoc comparisons indicated that the responses to equal offers $(M=2379 \mathrm{~ms}, S D=1194)$ were faster than responses to both unequal-disadvantageous $(M=3415 \mathrm{~ms}, S D=1222)[d=0.90$; CI: $0.66,1.14]$ and unequal-advantageous $(M=3233 \mathrm{~ms}, S D=1699)$ $[d=0.51$; CI: $0.29,0.72]$ offers, $p s<.001$. The responses to the unequal-disadvantageous and unequal-advantageous offers were not significantly different from each other, $p=.17[d=0.14$; CI: -0.06 , 0.34]. This pattern may suggest that the equal offers are processed heuristically: in this case the responses required significantly less time and less cognitive elaboration.

\section{Experiment 2}

In the first experiment, we tested different levels of inequality aversion when the utility was advantageous for the Self, an ingroup member or an outgroup member. We identified initial support for our hypotheses: individuals are prone to accept unequal offers when they are advantageous for the Self or an ingroup member, whereas they are more likely to reject the unequal-advantageous proposal when the beneficiary is an outgroup member. The second experiment was designed to replicate the first study results and address our hypothesis. For this aim, we replicated Experiment 1 in an online study. This experiment was designed to directly compare the ingroup and outgroup conditions; thus, we excluded the control condition. This modification relied on the findings of Experiment 1 in which the control and ingroup conditions showed the same pattern of acceptance. Furthermore, we investigated a potential moderating role of ingroup identification on the relationship between group membership and the outcome of the decision. It is possible that the pattern of results obtained in the first study mainly represented the decision-making of individuals who were highly identified with their ingroup and that did not follow the equality principle in order to increase their own group resources.

\section{Methods}

\subsection{Participants}

An a priori power analysis was conducted for sample size estimation (using GPower 3.1; Faul et al., 2007). With alpha $=0.05$ and power $=0.80$, the projected sample size needed to detect a medium to large effect size $\left(\mathrm{f}^{2}=0.15\right.$, Cohen, 1988) is approximately $N=74$ for an interaction between-within subjects mixed ANOVA with 2 condition and 3 measurements.

We recruited a slightly larger sample in order to deal with possible 
missing data. Thus, we advertised the study and enrolled 77 participants who took part in the study in exchange for course credits. The sample included 50 females $\left(M_{\text {age }}=26.27 ; S D_{\text {age }}=8.28\right)$. All participants were Italian citizens.

\subsection{Procedure}

All participants completed a short version of the bogus personality questionnaire as in Experiment 1 immediately before the TPUG. As in Experiment 1, it was explained that the questionnaire they completed was designed to assign them to one of two teams, Blue or Orange. Thus, on the basis of the fictitious personality test, the participants were randomly assigned to one of the two teams, and the number of participants who belonged to the two teams was balanced across conditions.

After the test feedback, the participants were asked 7-item Centrality scale (e.g., "Being a member of this group is an important reflection of who I am") drawn from Cameron's identification scale and translated in Italian (Cameron, 2004). They answered the questions on a 7-point Likert scale $(1=$ absolutely no; $7=$ absolutely yes $)$.

The TPUG general instructions were subsequently provided. The participants were informed that two other players were recruited: the first participant played the role of the proposer and had no membership; and the second participant played the role of the receiver and had a specific membership, Blue or Orange. The partners were fictitiously described as playing the game in real-time through an online network connection. The participants were led to believe that the proposer and the receiver would have received their part of the split at every accepted offer, whereas the responders did not receive utility.

After the general instruction, the membership manipulation was introduced. In the ingroup experimental condition, the third party (the receiver) was presented as an ingroup member (i.e., the same group Orange or Blue - of the responder); in the outgroup experimental condition, the third party was presented as an outgroup member. The participants did not receive additional clues on their identity. As in Experiment 1 , the participants in the ingroup condition $(N=40)$ played the TPUG in the role of the responder on the behalf of a samegroup receiver, and the participants in the outgroup $(N=37)$ condition played the role of the responder on the behalf of an other-group receiver. The procedure was thus analogous to that of Experiment 1 with several differences as a result of the fact that the experiment did not occur in the laboratory. As the experiment occurred online (through Inquisit web), to enhance our manipulation salience, a picture that contained a scheme of the roles of the game was presented: in this picture, the proposer was always represented by a black avatar, whereas the receiver and participant were represented by avatars colored according to the experimental condition (see Fig. 2). Moreover, we colored the frame in which the participants received the result of their assignments.

The offers were randomly administered by an Inquisit script that presented distributions as in Experiment 1 (offers 1:9; 2:8; 3:7; 4:6; 5:5; $6: 4 ; 7: 3 ; 8: 2 ; 9: 1$ ). Thus, we adopted a 2 (condition: ingroup vs outgroup) $\times 3$ (offer level: unequal-disadvantageous, equal, unequal-advantageous) experimental design with the first factor manipulated between subjects and the second factor manipulated within subjects. Every proposal was presented 5 times in random order for a total of 45 trials: since this experiment was administered on-line, the number of trials increased in order to grant greater reliability.

The participants responded by pressing the A key (accept) or the $\mathrm{R}$ key (reject) on the keyboard. After every accepted trial, the total amount gained by the receiver, which was constantly visible on the pc screen, was incremented of an amount equals to the part of the split destined to the receiver, whereas after a rejected trial, the total amount did not increase. The participant's response and the reaction time required to make a decision were recorded. During the game, the identities of the proposer and receiver did not change. To limit reputation biases (Bromley, 1993; Tetlock \& Manstead, 1985), the participants

\section{PROPOSER RECEIVER}
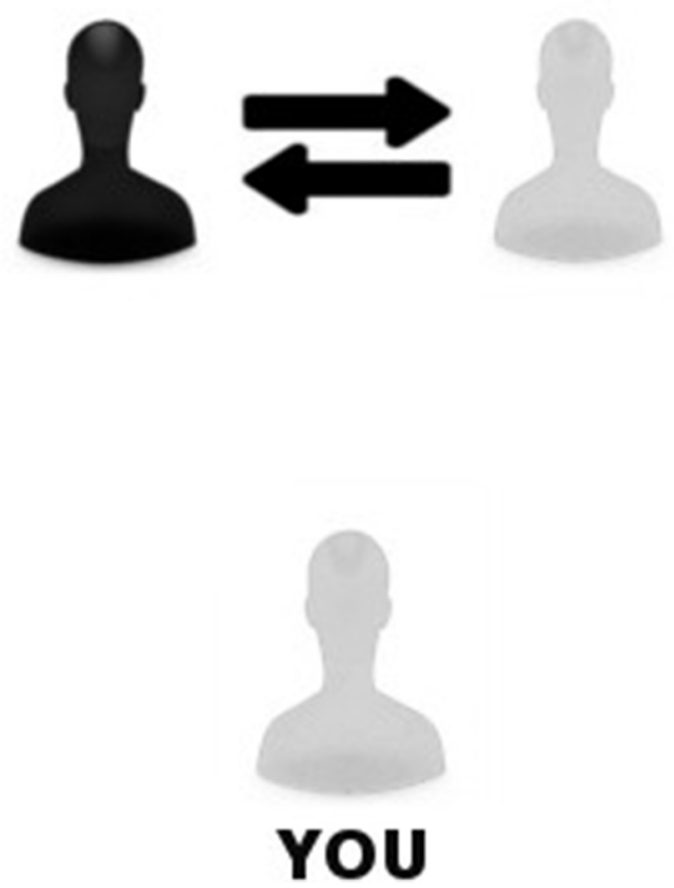

Fig. 2. Roles schema as presented to participants before each trial in Experiment 2.

were told that the other player and the experimenter would not discover their trial-by-trial choices.

At the end of the UG, the participants were properly debriefed.

\section{Results}

\subsection{Preliminary analyses}

We analyzed the data as in Experiment 1, averaging the dependent variable for the unequal-disadvantageous offers (from 1:9 to 4:6), equal offers (5:5) and unequal-advantageous offers (from 6:4 to 9:1). We preliminarily conducted a 2 (team: Blue vs Orange) $\times 2$ (condition: ingroup vs outgroup) $\times 3$ (offer level: unequal-disadvantageous, equal, unequal-advantageous) ANOVA on the acceptance index to rule out whether the participants' behavior was driven by their assigned team. This analysis indicated there was no significant main effect of team, $F(1$, $73)=0.77, p=.38, \eta^{2}=0.01$, or a significant interaction effect between the team and condition, $F(1,73)=3.40, p=.07, \eta^{2}=0.04$. Moreover, the analysis did not show any two- or three-way interaction effect including the variable team ( Fs $<3.40$, $\left.p s>.07, \eta^{2}<0.04\right)$. A similar ANOVA on reaction times yielded neither a main effect of team, $F(1,73)=0.03, p=.86, \eta_{\mathrm{p}}{ }^{2}<0.001$, nor a two- or three-way interactions involving the variable team (Fs $<0.55$, ps $>.46$, $\eta_{\mathrm{p}}{ }^{2}<0.01$ ). Thus, these analyses allowed us to exclude the variable team from further analysis.

\subsection{Main analyses}

As in the main analysis of Experiment 1 we conducted a 2 (condition: ingroup, outgroup) $\times 3$ (offer level: unequal-disadvantageous, equal, unequal-advantageous) ANOVA on the acceptance index, with the former factor varied between participants and the latter varied within-participants. The analysis revealed a significant main effect of the condition, $F(1,75)=10.73, p=.002, \quad \eta^{2}=0.12$ : post-hoc 
Table 2

Acceptance Index in the different experimental condition for different offer levels. Experiment 2.

\begin{tabular}{llll}
\hline & Unequal-disadvantageous & Equal & Unequal-advantageous \\
\hline Ingroup & $0.42(0.32)$ & $1.00(0.13)$ & $0.74(0.32)$ \\
Outgroup & $0.41(0.30)$ & $0.95(0.30)$ & $0.45(0.38)$ \\
Total & $0.42(0.30)$ & $0.97(0.14)$ & $0.60(0.36)$ \\
\hline
\end{tabular}

comparisons showed that overall in the ingroup condition acceptance rate $(M=0.72, S D=0.03)$ was higher than in outgroup condition $(M=0.61, S D=0.03), p=.002$ [ $d=0.68$; CI: 0.22, 1.14]. Moreover, as in Experiment 1, the ANOVA showed a main effect of the offer level, $F(1,75)=88.38, p<.001, \eta^{2}=0.54$ : the equal offers $(M=0.97$, $S D=0.14)$ were more likely to be accepted than both unequal-advantageous $(M=0.60, S D=0.36)[d=1.11$; CI: $0.82,0.1 .39]$ and unequal-disadvantageous offers $(M=0.42, S D=0.30), p s<.001$ $[d=1.64$; CI: $1.29,1.98]$. The difference between the unequal-advantageous and unequal-disadvantageous offers was significant, $p<.001[d=0.42$; CI: $0.18,0.65]$.

Consistent with our first study results, as displayed in Table 2, the analysis identified a significant interaction effect between the condition and offer level, $F(1,75)=6.00, p=.02, \eta^{2}=0.07$. This interaction was significant even re-including in the ANOVA the team to which the participant was assigned, $F(1,73)=6.46, p=.01, \eta^{2}=0.08$. As revealed by post-hoc comparisons (LSD test), in the case of unequal-disadvantageous offers there was no significant difference between the ingroup $(M=0.42, S D=0.32)$ and outgroup $(M=0.41, S D=0.30)$ conditions, $p=.94[d=0.04$; CI: $-0.41,0.48]$. The same was true between the ingroup $(M=1.00, S D=0.13)$ and outgroup $(M=0.95$, $S D=0.30$ ) conditions for equal levels of offer even if with a lower degree of certainty, $p=.08$ [ $d=0.41$; CI: $-0.05,0.86]$. Most importantly, the analysis revealed a significant difference between ingroup $(M=0.74, S D=0.32)$ and outgroup $(M=0.45, S D=0.38)$ conditions in the case of unequal-advantageous offers $(p<.001$ $[d=0.84$; CI: $0.37,1.31])$. In this case, the participants rejected less unequal-advantageous offers when the utility was in favor of an ingroup member rather than an outgroup member. Moreover, in the outgroup condition, the unequal-advantageous offers $(M=0.45, S D=0.06)$ and the unequal-disadvantageous ones $(M=0.41, S D=0.05)$ were rejected at the same degree $p=.57[d=0.10$; CI: $-0.23,0.42]$. In contrast, in the ingroup condition, the unequal-advantageous offers $(M=0.74$, $S D=0.32$ ) were rejected less frequently than unequal-disadvantageous ones $(M=0.42, S D=0.30), p<.001[d=0.74$; CI: 0.39, 1.09].

As in Experiment 1, we re-analyzed the data using a generalized linear mixed model. The condition variable was introduced as a categorical variable using ingroup as the reference group, and level of offer was introduced as a continuous predictor ranging from 1 (the most disadvantageous for the responder) to 9 (the most advantageous for the responder). The dependent variable was the decision outcome and accepted offers were coded as 1 and rejected offers were coded as 0 . We employed a logistic link function. The analysis yielded a main effect of the offer level $(\mathrm{B}=0.74, \mathrm{SE}=0.14, z=5.31, p<.001$ ), indicating that the participants were more likely to reject disadvantageous and to accept advantageous offers. Moreover, a significant interaction between the offer level and condition arose $(\mathrm{B}=-0.64, \mathrm{SE}=0.19, z=-3.30$, $p<.001$ ), revealing that the participant in the outgroup condition tended to reject more offers as offer level increases, if compared to participants in the ingroup condition.

\subsection{Moderation}

Besides replicating the findings of Experiment 1, this study aimed to investigate the possible moderating role of ingroup identification on the process. For this purpose, the items of the ingroup identification scale were averaged ( $\alpha=0.84$ ) and the identification index was computed $(M=3.89, S D=1.25)$. A PROCESS macro (Hayes, 2013) was subsequently used to test a moderated moderation model (model 3; 10,000 bootstrapped resampling). This analysis tested a moderated-moderation in which the main independent variable was the experimental condition ( 0 = ingroup, $1=$ outgroup $)$ as a categorical variable, the offer level was the first moderator ( $1=$ unequal-disadvantageous, $2=$ equal, 3 = unequal-advantageous), the ingroup identification was the second continuous moderator, and the acceptance index was the dependent variable. The analysis showed a non-significant three-way interaction between the condition, offer and ingroup identification $(\mathrm{B}=-0.03$, $\mathrm{SE}=0.05, t=-0.70, p=.48$, CI: $\mathrm{LL}=-0.12$, UL $=0.06)$, that did not increase the explained variance of the model $\left(\Delta \mathrm{R}^{2}=0.002, F(1\right.$, 223) $=0.51, p=.48$ ).

This evidence suggested that the difference between ingroup and outgroup condition for unequal-advantageous offers was robust so far, and that the level of identification with the ingroup did not affect the decision outcome in our task.

\subsection{Reaction times}

Finally, to explored the heuristic processing of equal offers suggested by Experiment 1 results. We conducted the same 2 (condition: ingroup vs outgroup) $\times 3$ (offer level: unequal-disadvantageous, equal, unequal-advantageous) ANOVA with the reaction time as a dependent variable. This analysis did not show a significant main effect of the condition, $F(1,75)=0.05, p=.82, \eta^{2}<0.001$, or the interaction between condition and offer level, $F(1,75)=1.56, p=.22, \eta^{2}=0.02$. As in Experiment 1, the analysis identified a significant main effect of the offer level, $F(1,75)=22.55, p<.001, \eta^{2}=0.23$. Post-hoc comparisons revealed that the equal offers $(M=1819 \mathrm{~ms}, S D=910)$ were processed significantly faster than both unequal-disadvantageous $(M=2503 \mathrm{~ms}, S D=1102)$ [ $d=0.60$; CI: $0.36,0.85]$ and unequaladvantageous $(M=2401 \mathrm{~ms}, S D=916)[d=0.63$; CI: $0.39,0.88]$, $p s<.001$. The unequal-disadvantageous and unequal-advantageous offers did not differ from each other, $p=.30[d=0.12$; CI: -0.11 , 0.35].

\section{Experiment 3}

So far, we investigated inequality aversion when the utility was advantageous for an ingroup member rather than an outgroup member. Our main hypothesis that individuals are more prone to accept unequal offers when they are advantageous for an ingroup member than for an outgroup member still holds. Moreover, in Experiment 2, the potential moderating role of ingroup identification was explored but it did not receive empirical support. Therefore, in Experiment 3, we explored alternative mechanism likely to explain our results. Specifically, we hypothesized that the perceived intergroup competition might influence the process and moderate the interaction between experimental condition and the offer level. Our hypothesis was that participants perceiving high level of competition between ingroup and outgroup would have taken advantage of their responders' position and, thus, would have accepted less unequal-advantageous offer for an outgroup member in order to reduce its resources. In contrast, participants perceiving low level of intergroup competition were expected not to show such a bias. Hence, in line with Brewer (1999)'s assumption that attachment to one's ingroup does not necessarily require hostility toward outgroups, we reasoned that perceived antagonism between ingroup and outgroup could be more effective in moderating our effect than identification with the ingroup.

To explore this hypothesis, we assessed the perceived competition between groups, as well as the ingroup identification. Both measures were presented to the participants after the TPUG they played. As before, participants were randomly assigned to take part in a TPUG as responders for an ingroup or an outgroup member. 


\section{Methods}

\subsection{Participants}

An a priori power analysis was conducted for sample size estimation (using GPower 3.1; Faul et al., 2007). With alpha $=0.05$ and power $=0.80$, the projected sample size needed to detect a medium to large effect size ( $\mathrm{f}^{2}=0.15$, Cohen, 1988) is approximately $N=74$ for an interaction between-within subjects mixed ANOVA with 2 condition and 3 measurements.

We advertised the study online and let participant to enroll in the study by clicking a web link. Given the online nature of the study, we introduced four questions to check whether participant understood the task. Participants who did not completed the study or failed the test were excluded. The final sample included 121 participants ( 99 female), all aged between 19 and $35\left(M_{\text {age }}=23.39 ; S D_{\text {age }}=3.44\right)$.

\subsection{Procedure}

At the beginning of the experiment, the participants were informed of the procedure and the informed consent was presented on the screen. Participants agreed to participate in the experiment by clicking the "I Agree" button.

After agreeing, all participants completed a bogus questionnaire as in previous experiments. After the questionnaire, participants were assigned to one of the two teams, Blue or Orange. The number of participants who belonged to the two teams was balanced across conditions. The random assignment the participants to one of the two teams and the random membership of the receiver yielded two experimental conditions: the ingroup condition $(N=58)$, when the participant and the receiver belonged to the same team and the outgroup condition $(N=63)$, when the participant and the receiver belonged to different teams. After the assignment, we provided the instructions of the TPUG and asked four questions in order to check whether participants understood correctly the task and the consequences of their decisions. We presented a fake proposal between the proposer and the receiver (eg. "PROPOSER: A - RECEIVER: B") and we asked how much the receiver and the proposer would have received in case of offer acceptance or rejection. Only participants who answered correctly were included. The TPUG started right after this check.

The procedure was thus analogous to that of Experiments 1 and 2. Each proposal was presented with the label "PROPOSER" and the part of the split destined to it colored in black, while the label "RECEIVER" and the remaining part of the split was colored in the color of the receiver's team.

The offers were randomly picked from all possible gain combination (offers $1: 9 ; 2: 8 ; 4: 6 ; 5: 5 ; 6: 4 ; 8: 2 ; 9: 1$ ). Every proposal was presented four times in a random order. The participants responded by pressing clicking the button "ACCEPT" or the button "REJECT" on the screen. The participant's decisions were recorded. During the game, the identities of the proposer and receiver did not change.

Thus, we adopted a 2 (condition: ingroup vs outgroup) $\times 3$ (offer level: unequal-disadvantageous, equal, unequal-advantageous) experimental design with the first factor manipulated between subjects and the second factor manipulated within subjects.

At the end of the TPUG participants answered 3 items measuring ingroup identification ("People of my group and I are very similar", "People of my group and I are very close" and "Our group is very cohesive"). Such items were designed to measure to what extent participants' selves overlapped with their own ingroup. Next, participants were asked 3 items assessing perceived intergroup competition on a 7-point Likert scale ("Members of my team deserve to receive more money", "There is a competition going on between the Blue and the Orange" and "I want to be sure that members of the other team receive less money"). Participants answered the questions on a 7-point scale ranging from 1 (=absolutely not) to 7 (=absolutely yes).

\section{Results}

\subsection{Preliminary analyses}

We analyzed the data as in previous experiments, averaging the dependent variable for unequal-disadvantageous offers (from 1:9 to 4:6), equal offers (5:5) and unequal-advantageous offers (from 6:4 to 9:1).

We preliminarily conducted a 2 (team: Blue vs Orange) $\times 2$ (condition: ingroup vs outgroup) $\times 3$ (offer level: unequal-disadvantageous, equal, unequal-advantageous) ANOVA on the acceptance index to explore whether the participants' behavior was driven by their assigned team. This analysis indicated a non-significant main effect of team, $F(1$, $117)=1.31, p=.26, \eta^{2}=0.01$, and a non-significant interaction between team and condition, $F(1,117)=0.01, p=.91, \eta^{2}<0.01$. Moreover, the two- or three-way interactions including the variable team were non-significant, $F s<1.92$, $p s>.17, \eta^{2}<0.02$. Thus, as in previous experiments, we excluded the variable team from further analyses.

\subsection{Main analyses}

We conducted a 2 (condition: ingroup vs outgroup) $\times 3$ (offer level: unequal-disadvantageous, equal, unequal-advantageous) ANOVA on the acceptance index with the first factor varied between participants and the second one varied within participants. This analysis indicated a significant main effect of condition, $F(1,119)=7.90, p=.006$, $\eta^{2}=0.06$. Participants in ingropup condition $(M=0.75, S D=0.33)$ accepted more offers than participants in outgroup condition $(M=0.66, S D=0.37), p=.006$.

Moreover, in line with previous literature the analysis yielded a main effect of offer level, $F(1,119)=131.23, p<.001, \eta^{2}=0.52$. Consistent with the prior two studies, post-hoc comparisons showed that equal offers $(M=0.98, S D=0.11)$ were more likely to be accepted than both unequal-advantageous $(M=0.68, S D=0.35)[d=2.7$; CI: $1.75,2.38]$ and unequal-disadvantageous offers $(M=0.44, S D=0.31)$, $p s<.001$ [ $d=5.00$; CI: 4.49, 5.51]; moreover, the difference between unequal-disadvantageous and unequal-advantageous was significant, $p<.001$ [ $d=0.48$; CI: 0.29, 0.74].

Crucially, in line with previous experiments, the analysis yielded an interaction between condition and offer level, $F(1,119)=3.90$, $p=.05, \eta^{2}=0.03$. Re-including the factor team in the ANOVA, the interaction effect was marginally significant, $F(1,117)=3.62$, $p=.059, \eta^{2}=0.03$. Post-hoc comparisons revealed that at both equal and unequal-disadvantageous of offer levels, participants' decisions in ingroup (unequal-disadvantageous, $M=0.46, \quad S D=0.32$; fair, $M=0.99, S D=0.03$ ) and in outgroup condition (unequal-disadvantageous, $M=0.42$, $S D=0.31$; fair, $M=0.96, S D=0.15$ ) did not differ ( $p s>.12$, LSD). However, participants in ingroup condition ( $M=0.78, S D=0.29)$ were significantly $(p=.002)$ more likely to accept unequal-advantageous offers than participants in outgroup condition $(M=0.58, S D=0.38)[d=0.88$; CI: $0.51,1.26]$. Such a difference confirmed our main hypothesis (Table 3 ).

As in prior studies, we re-analyzed the decision to accept or reject the offers via a generalized linear mixed model using the same procedure described in Experiments 1 and 2. The effect of offer level proved

Table 3

Acceptance Index in the different experimental condition for different offer levels. Experiment 3.

\begin{tabular}{llll}
\hline & Unequal-disadvantageous & Equal & Unequal-advantageous \\
\hline Ingroup & $0.46(0.32)$ & $0.99(0.03)$ & $0.78(0.29)$ \\
Outgroup & $0.42(0.31)$ & $0.96(0.15)$ & $0.58(0.38)$ \\
Total & $0.44(0.31)$ & $0.98(0.11)$ & $0.68(0.35)$
\end{tabular}


to be significant $(\mathrm{B}=0.39, \mathrm{SE}=0.02, z=15.96, p<.001$ ). More importantly, the analysis revealed a significant interaction between offer level and condition. This interaction $(B=-0.21, S E=0.03$, $z=-6.85, p<.001$ ) indicates that, if compared to ingroup condition, participants in outgroup condition were less likely to accept the offer as the amount destined to the receiver increased. This finding is in line with our main hypothesis that decision-makers are less prone to accept unequal-advantageous offers when directed to outgroup members than to ingroup members.

\subsection{Moderation}

As in Experiment 2, first we tested the moderating role of ingroup identification. We obtained an identification score $(M=3.60$, $S D=1.45$ ) averaging the three items presented after the TPUG $(\alpha=0.82)$. We tested whether the interaction between offer level and experimental condition depends on the identification with the ingroup.

Specifically, in order to analyze this moderated-moderation, we employed a PROCESS macro (Hayes, 2013; model 3). In the model $(10,000$ bootstrapped resampling), we used the experimental condition ( $0=$ ingroup, $1=$ outgroup) as a categorical independent variable, the offer level as first moderator ( 1 = unequal-disadvantageous, $2=$ equal, 3 = unequal-advantageous), ingroup identification as second continuous moderator, and the acceptance index as dependent variable.

Our analysis revealed that nor the interaction between our experimental condition and offer level $(\mathrm{B}=0.05, \mathrm{SE}=0.12, t=0.45$, $p=.65$, CI: $\mathrm{LL}=-0.18$, UL $=0.29$ ), neither the three-way interaction between condition, offer and ingroup identification $(B=-0.04$, $\mathrm{SE}=0.03, t=-1.21, p=.23$, CI: $\mathrm{LL}=-0.10, \mathrm{UL}=0.02$ ) were significant. Moreover, the addition of the three way interaction did not significantly increased the explained variance of the model $\left(\Delta \mathrm{R}^{2}=0.004, F(1,355)=1.47, p=.23\right)$. Thus, in line with the second experiment, this result suggested that the identification with the ingroup did not impact the interaction effect between experimental condition and offer level on the decision-making.

Then, to test the role of perceived intergroup competition as moderator, we computed a competition score $(M=1.88, S D=1.24)$ averaging the three items presented after the TPUG $(\alpha=0.78)$. The score of identification and of competition proved to be significantly related $(r=0.37, p<.007)$; the low level of variance inflation factor (VIF $=1.15$ ) suggested a low level of multicollinearity between the two variables.

After verifying the independence between identification and competition, we tested whether the interaction between offer level and experimental condition depends on perceived competition. To this aim, we examined the same moderated moderation model (PROCESS macro, model 3, 10,000 bootstrapped resampling; Hayes, 2013) using intergroup competition as second moderator. Specifically, we used the experimental condition ( $0=$ ingroup, $1=$ outgroup) as categorical independent variable, the offer level as first moderator ( $1=$ unequaldisadvantageous, 2 = equal, 3 = unequal-advantageous), the perceived intergroup competition as second continuous moderator, and the acceptance index as dependent variable.

The moderation model (see Fig. 3) showed a significant interaction between our experimental condition and offer level $(\mathrm{B}=0.12$, $\mathrm{SE}=0.08, t=2.27, p=.02, \mathrm{CI}: \mathrm{LL}=0.02, \mathrm{UL}=0.33$ ) and a significant three-way interaction between condition, offer and perceived competition $(\mathrm{B}=-0.13, \quad \mathrm{SE}=0.03, \quad t=-3.89, \quad p<.001, \quad \mathrm{CI}$ : $\mathrm{LL}=-0.20, \mathrm{UL}=-0.07)$ which significantly increased the explained variance of the model $\left(\Delta \mathrm{R}^{2}=0.04, F(1,335)=15.13, p<.001\right)$. For low $(\mathrm{B}=0.04, \mathrm{SE}=0.05, t=0.80, p=.42, \quad \mathrm{CI}: \mathrm{LL}=-0.014$, $\mathrm{UL}=0.1457)$ and medium $(\mathrm{B}=-0.08, \mathrm{SE}=0.04, t=-1.80$, $p=.07$, CI: $\mathrm{LL}=-0.1613$, UL $=0.0071$ ) levels of perceived intergroup competition, the interaction between offer level and experimental condition was not statistically significant. However, for high level of perceived intergroup competition $(B=-0.24$, $S E=0.06$, $t=-4.03, p<.001$, CI: $\mathrm{LL}=-0.3628, \mathrm{UL}=-0.1247)$ the critical interaction was significant. This pattern of results indicated that only participants who perceived a high level of intergroup competition were less prone to accept unequal-advantageous offers on the behalf of the outgroup member than of the ingroup member. The effect disappeared for participants who did not perceive antagonism between ingroup and outgroup.

\section{Experiment 4}

In the first three experiments, we investigated different levels of inequality aversion when the utility was advantageous for an ingroup member rather than an outgroup member. We identified initial support for our hypotheses: individuals are more prone to accept unequal offers when they are advantageous for an ingroup member, whereas they are more likely to reject unequal-advantageous proposals when the beneficiary is an outgroup member. This fourth experiment was designed to explore the robustness of this effect and its boundary conditions. For this aim, in Experiment 4, we bounded the recipient's utility to the decision-maker's utility by giving the decision-maker (i.e., the participant) the same reward converted in candies that $\mathrm{s} /$ he gained on the behalf of the third party. Furthermore, to investigate the role of the group membership in this condition, we introduced a measure of ingroup identification.

\section{Methods}

\subsection{Participants}

The sample included 61 participants (41 female), all aged between 20 and $33\left(M_{\text {age }}=23.54 ; S D_{\text {age }}=4.59\right)$, who participated to the experiment in exchange for course credits and real rewards (in candies). This was a convenience sample since we advertised the study during inclass activities and enrolled all individuals who responded and volunteered to participate.

\subsection{Procedure}

All participants completed the same bogus personality questionnaire as in Experiment 1. It was completed 7 days before the laboratory experiments were conducted.

Upon their arrival at the laboratory, the participants were informed of the procedure and read and signed the informed consent. As in previous experiments, it was explained that the questionnaire they completed was designed to assign them to one of the same two teams, Blue or Orange. After the assignment, we asked them to wear a shirt of the color of their team to make their team membership more vivid. The participants were randomly assigned to one of the two teams, and the number of participants who belonged to the two teams was balanced across conditions. As in Experiment 1, the participants in the control condition $(N=20)$ played the role of the responder and receiver as in the standard version of the UG; in the ingroup condition $(N=21)$, they played the TPUG in the role of the responder on the behalf of a samegroup receiver, and in the outgroup condition $(N=20)$, they played the role of the responder on the behalf of an other-group receiver.

The procedure was thus analogous to that of Experiments 1, 2 and 3; however, in this fourth study, the participants received the same utility they gathered for their third party converted in candies. For this purpose, they were provided with a table that reported the exchange criteria (10 euro $=1$ candy). This modification was introduced to determine whether the participants showed inequality aversion in the outgroup condition even if it would affect their own payoff.

The offers were randomly administered by an Inquisit script that presented distributions as in previous experiments (offers 1:9; 2:8; 4:6; $5: 5 ; 6: 4 ; 8: 2 ; 9: 1)$. Every proposal was presented three times in a random order. The participants responded by pressing the A key 


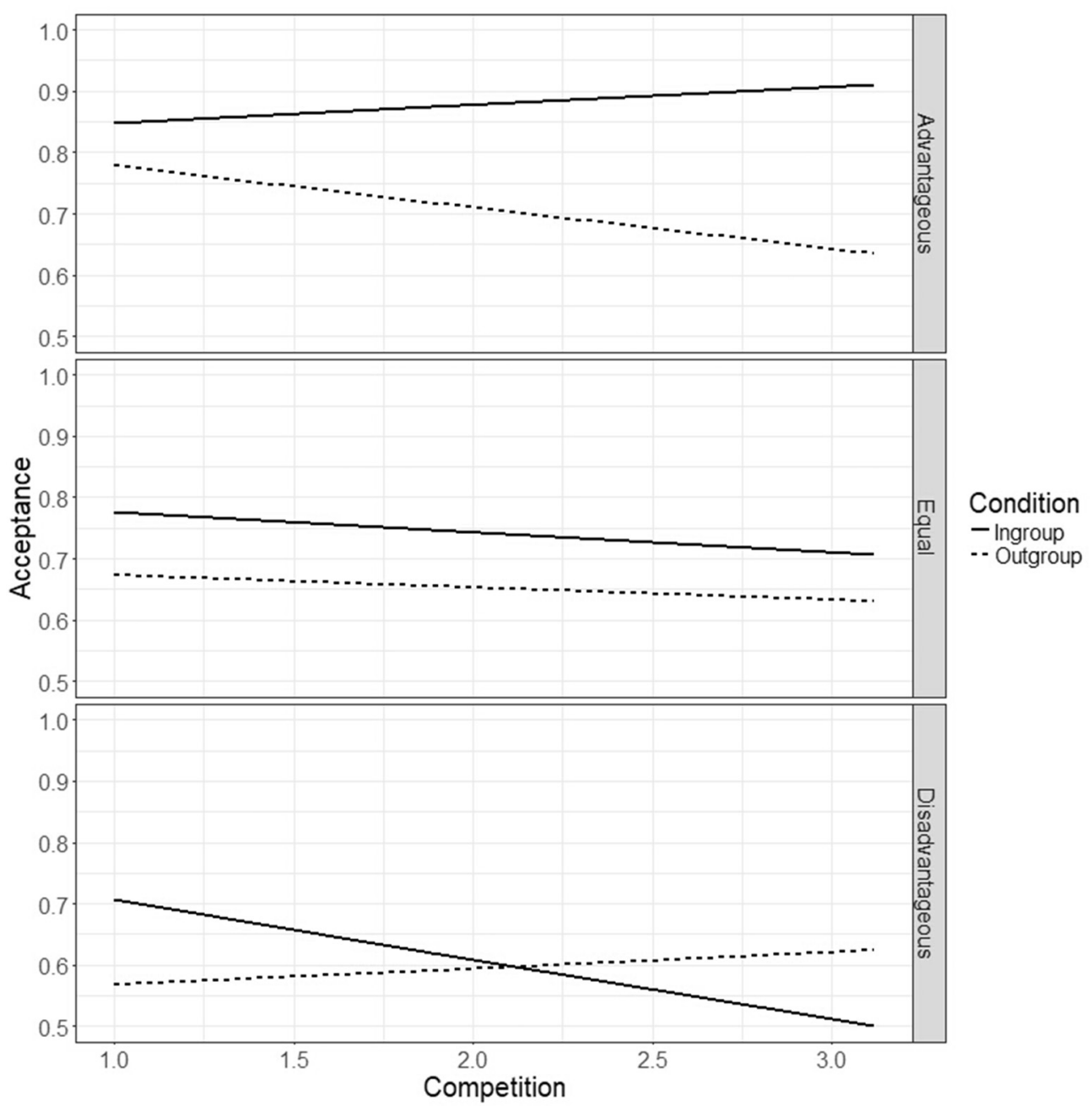

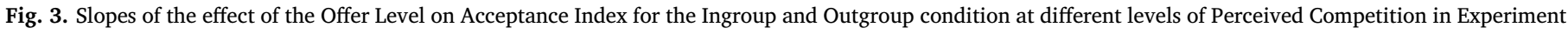
3.

(accept) or the R key (reject) on the keyboard. After every accepted trial, the gained total amount, which was constantly visible on the pc screen, was incremented of an amount equals to the part of the split destined to the receiver, whereas after a rejected trial, the total amount did not increase. The participant's response and the reaction time required to make a decision were recorded. During the game, the identities of the proposer and receiver did not change.

Thus, we adopted a 3 (condition: control, ingroup, outgroup) $\times 3$ (offer level: unequal-disadvantageous, equal, unequal-advantageous) experimental design with the first factor manipulated between subjects and the second factor manipulated within subjects. At the end of the task, the participant answered 3 items that measured ingroup identification on a 7-point Likert scale (i.e., "I feel to belong to the group of which I'm wearing a t-shirt", "We with the same color t-shirt are members of the same group" and "Participants with different color t-shirt belong to different groups").

Finally, the participants were properly debriefed, and because they were playing for real rewards, the accumulated amount was converted into candies.

\section{Results}

\subsection{Preliminary analyses}

We analyzed the data as in Experiments 1,2 and 3, averaging the dependent variable for unequal-disadvantageous offers (from 1:9 to
4:6), equal offers (5:5) and unequal-advantageous offers (from 6:4 to 9:1).

We preliminarily conducted a 2 (team: Blue vs Orange) $\times 3$ (condition: control, ingroup, outgroup) $\times 3$ (offer level: unequal-disadvantageous, equal, unequal-advantageous) mixed ANOVA on the acceptance index to rule out whether the participants' behavior was driven by their assigned team. This analysis indicated there was no significant main effect of team, $F(1,55)=0.21, p=.65, \eta^{2}=0.01$, and a non-significant interaction between team and condition, $F(2$, $55)=0.78, p=.46, \eta^{2}=0.03$. Moreover, no significant two- or threeway interactions including the variable team were identified $\left(F s<1.04, p s>.31, \eta^{2}<0.02\right)$. An analogous ANOVA on the reaction times indicates there was no main effect of team, $F(1$, $55)=0.99, p=.33, \eta_{\mathrm{p}}{ }^{2}<0.02$, or a two- or three-way interactions involving the variable team ( Fs $<1.68$, ps $>.20, \eta_{\mathrm{p}}{ }^{2}<0.05$ ). Thus, as in previous experiments, we excluded the variable team from further analysis.

\subsection{Main analyses}

We conducted a 3 (condition: control, ingroup, outgroup) $\times 3$ (offer level: unequal-disadvantageous, equal, unequal-advantageous) ANOVA on the acceptance index with the first factor varied between participants and the second one varied within participants. This analysis indicated there was no significant main effect of condition, $F(2$, 58) $=0.60, p=.55, \eta^{2}=0.02$; however, there was a main effect of 
Table 4

Acceptance Index in the different experimental condition for different offer levels. Experiment 4.

\begin{tabular}{llll}
\hline & Unequal-disadvantageous & Equal & Unequal-advantageous \\
\hline Control & $0.43(0.28)$ & $0.97(0.13)$ & $0.87(0.22)$ \\
Ingroup & $0.43(0.28)$ & $0.94(0.14)$ & $0.79(0.27)$ \\
Outgroup & $0.43(0.27)$ & $0.94(0.13)$ & $0.77(0.27)$ \\
Total & $0.43(0.27)$ & $0.95(0.14)$ & $0.81(0.27)$ \\
\hline
\end{tabular}

offer level, $F(1,58)=77.24, p<.001, \eta^{2}=0.57$.

Consistent with previous experiments, post-hoc comparisons showed that equal offers $(M=0.95, S D=0.14)$ were more likely to be accepted than both unequal-advantageous $(M=0.81, S D=0.27)$ $[d=0.48$; CI: $0.21,0.74]$ and unequal-disadvantageous offers $(M=0.43, S D=0.27), p s<.001[d=0.1 .85$; CI: $1.43,2.26]$; moreover, the difference between unequal-disadvantageous and unequaladvantageous was significant, $p<.001$ [ $d=0.91$; CI: $0.61,1.21$ ]

In contrast to the previous experiments, as Table 4 shows, the analysis did not yield an interaction effect between condition and offer level, ${ }^{1} F(2,58)=0.29, p=.75, \eta^{2}=0.01$. Such interaction remained equally non-significant even including in the ANOVA the team to which the participant was assigned, $F(2,55)=0.28, p=.76, \eta^{2}=0.01$. The lack of interaction may be a result of the more conservative design of this third experiment, in which the decision-maker utility was bounded to the receiver's utility.

Similar to prior studies, we re-analyzed the decision to accept or reject the offers via a generalized linear mixed model using the same procedure described before. The effect of offer level remained significant ( $\mathrm{B}=1.01, \mathrm{SE}=0.27, z=3.74, p<.001)$; however, the analysis did not yield a significant interaction between offer level and condition. This interaction was not significant when we compared ingroup and control conditions $(\mathrm{B}=0.28, \mathrm{SE}=0.38, z=0.73, p=.46)$ or when we compared ingroup and outgroup conditions $(B=-0.18$, $\mathrm{SE}=0.37, z=-0.48, p=.63$ ).

\subsection{Moderation}

To investigate the role of ingroup identification as moderator, an identification index was computed $(M=3.78, S D=1.31)$ averaging the three items presented in the questionnaire $(\alpha=0.65)$. A PROCESS macro (Hayes, 2013) was subsequently used to test a moderated moderation model (model $3 ; 10,000$ bootstrapped resampling). In the model, we used the experimental conditions ( $0=$ ingroup, $1=$ outgroup) as a categorical independent variable, the offer level as a first moderator ( 1 = unequal-disadvantageous, 2 =equal, $3=$ unequal-advantageous), the ingroup identification as a second continuous moderator, and the acceptance index as a dependent variable.

The moderation model (see Fig. 4) showed a significant interaction between our experimental condition and offer level $(B=0.40$, $\mathrm{SE}=0.19, t=2.06, p=.04, \mathrm{CI}: \mathrm{LL}=0.01, \mathrm{UL}=0.78)$ and a significant three-way interaction between condition, offer and ingroup identification $(\mathrm{B}=-0.11, \quad \mathrm{SE}=0.05, \quad t=-2.25, \quad p=.03, \quad \mathrm{CI}$ : $\mathrm{LL}=-0.20, \mathrm{UL}=-0.01)$ which significantly increased the explained variance of the model $\left(\Delta \mathrm{R}^{2}=0.03, F(1,115)=5.06, p=.026\right)$.

For the low and medium offer levels (i.e., unequal-disadvantageous and equal) and independent from the ingroup identification, the experimental condition did not affect the participants' decision-making ( $p s>.27$ ) in line with the ANOVA results. In contrast, for the high offer level (i.e., unequal-advantageous) and high level of identification with the ingroup (5.15), the experimental condition significantly impacted the participants' acceptance $(\mathrm{B}=-0.21, \mathrm{SE}=0.10, t=-2.01$,

\footnotetext{
${ }^{1}$ The interaction effect between condition and offer level did not change including gender as covariate in the four studies.
}

$p=.046$, CI: $\mathrm{LL}=-0.42$, $\mathrm{UL}=-0.003$ ) so that the respondents were more prone to reject the offer when the receiver of the favorable division was an outgroup rather than ingroup member. When the identification with the ingroup was low (2.49), the effect of condition on the acceptance of high offers disappeared $(\mathrm{B}=0.17, \mathrm{SE}=0.10, t=1.66$, $p=.10$, CI: $\mathrm{LL}=-0.03$, UL $=0.38$ ).

This interaction provides clear evidence that the acceptance ratio of unequal-advantageous offers decreased in the outgroup condition for participants who felt highly identified with their ingroup despite the condition that the receivers' utility was bound to their own gain.

To provide the full picture of the contrasts among conditions we recomputed the same model contrasting the control condition against the ingroup condition and again the control condition against the outgroup condition.

For the former pair of conditions, the model used the experimental conditions ( $0=$ control, $1=$ ingroup) as a categorical independent variable and the same moderators as before. The dependent variable was again the acceptance index. This time the moderation model did not show an interaction between the experimental condition and offer level $(\mathrm{B}=0.08, \mathrm{SE}=0.19, t=0.45, \quad p=.65, \quad \mathrm{CI}: \mathrm{LL}=-0.29$, $\mathrm{UL}=0.47)$ indicating that the slopes of the control and ingroup condition did not differ. We did not identify a three-way interaction between condition, offer and ingroup identification $(\mathrm{B}=-0.03$, $\mathrm{SE}=0.05, t=-0.78, p=.44$, CI: $\mathrm{LL}=-0.13, \mathrm{UL}=0.06$ ) indicating that these slopes were not influenced by the identification level.

For the latter pair the comparison was between the control and outgroup conditions. Once again we used the experimental conditions ( $0=$ control, $1=$ outgroup) as a categorical independent variable, the same moderators, and the acceptance index as a dependent variable. The results of this analysis resembled the results of the model contrasting the ingroup and outgroup conditions. The model showed a significant interaction between the experimental condition and offer level $(\mathrm{B}=0.49, \quad \mathrm{SE}=0.19, \quad t=2.63, \quad p<.01, \quad \mathrm{CI}: \quad \mathrm{LL}=0.12$, $\mathrm{UL}=0.85)$ and a significant three-way interaction between the condition, offer and ingroup identification $(B=-0.15, S E=0.05$, $t=-3.08, p<.01$, CI: $\mathrm{LL}=-0.24$, $\mathrm{UL}=-0.05)$ which significantly increased the explained variance of the model $\left(\Delta \mathrm{R}^{2}=0.06, F\right.$ $(1,112)=9.84, p<.01)$.

Taken together the similarity between the results of the first (ingroup vs outgroup) and the third (control vs outgroup) analyses and the lack of difference between the control and ingroup conditions in the second analysis suggest that a reduction of the acceptance index in the outgroup condition as identification with the ingroup increases.

\subsection{Reaction times}

Finally, we conducted the 3 (condition: control, ingroup, outgroup) $\times 3$ (offer level: unequal-disadvantageous, equal, unequal-advantageous) ANOVA on the reaction times. This analysis did not show a significant main effect of the condition, $F(2,58)=0.35, p=.71$, $\eta^{2}=0.01$, or a significant interaction between the offer level and condition, $F(2,58)=1.33, p=.27, \eta^{2}=0.04$. In line with previous studies, the ANOVA revealed a main effect of the offer level, $F(1$, $58)=32.39, \quad p<.001, \eta^{2}=0.358$ : equal offers $(M=2488 \mathrm{~ms}$, $S D=1392)$ were processed significantly faster than both unequal-disadvantageous $(M=3916 \mathrm{~ms}, S D=1713)[d=1.04$; CI: $0.73,1.35$ ] and unequal-advantageous $(M=3325 \mathrm{~ms}, S D=1552)[d=0.59$; CI: $0.32,0.86]$, $p s<.001$. The difference between unequal-advantageous and unequal-disadvantageous was statistically significant, $p<.01$ $[d=0.43$; CI: $0.16,0.69]$. This finding supported our hypothesis that equal offers require less cognitive processing than unequal ones.

\section{Small-scale meta-analysis}

In our four experiments, we obtained consistent evidence regarding the effect of the receiver's membership on the responder's decision- 


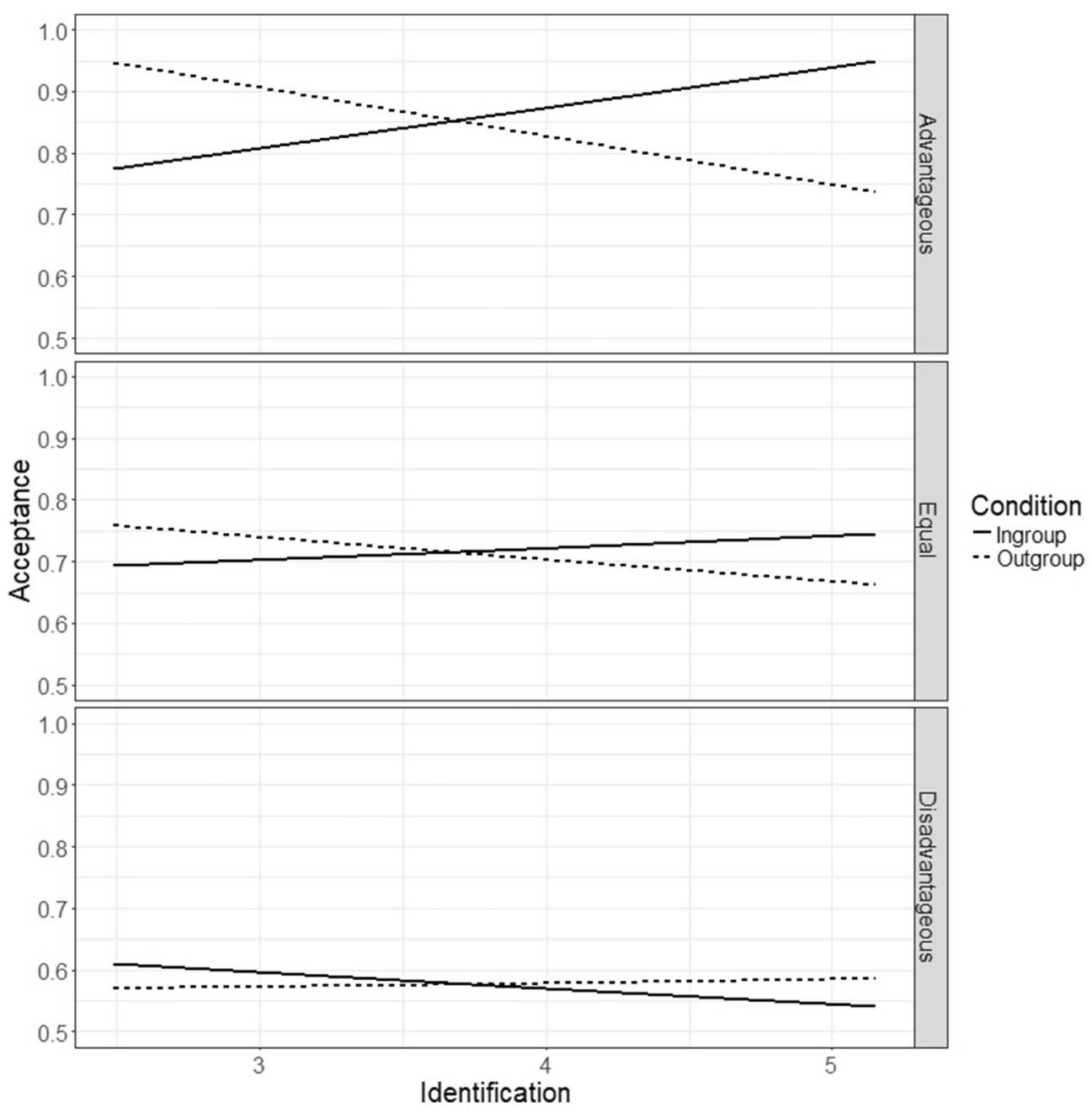

Fig. 4. Slopes of the effect of the Offer Level on Acceptance Index for the Ingroup and Outgroup condition at different levels of Ingroup Identification in Experiment 4.

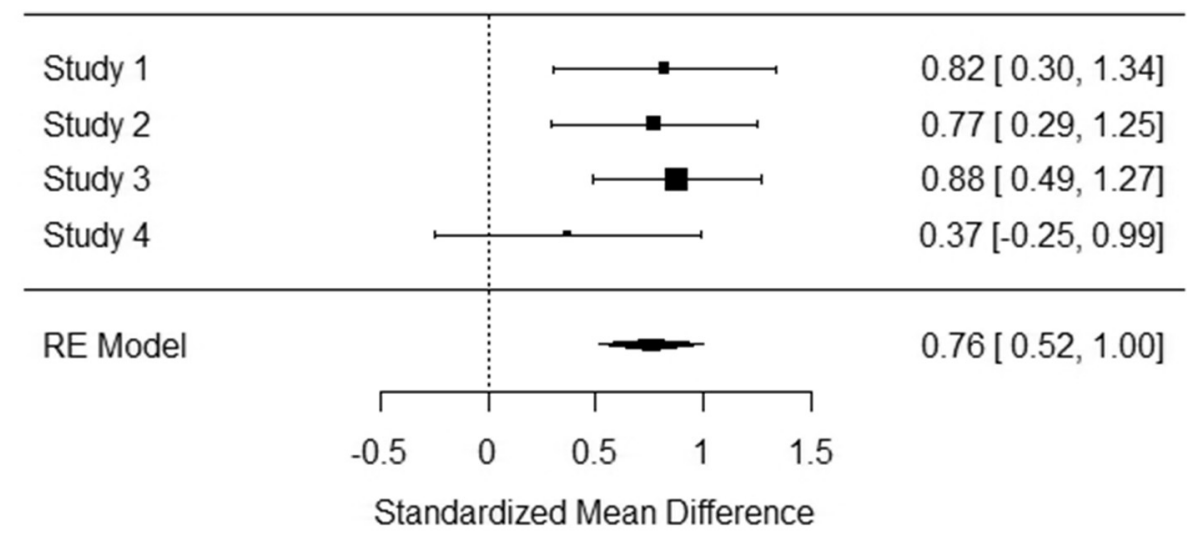

Fig. 5. Forest plot of the aggregated difference between the Ingroup and Outgroup conditions for the Unequal-Advantageous offers.

making during a TPUG. Although our experiments provided the first empirical support to our hypothesis, we computed a small-scale metaanalysis to combine the results obtained in these different studies and increase the precision of the parameter estimates. To this aim, we combined the effects on the acceptance index of unequal-advantageous offers between the ingroup and outgroup conditions. Such effects were showed a statistically acceptable homogeneity $(\mathrm{Q}(3)=1.93, p=.57)$. As we assumed that our effects were drawn from a distribution of effects, we used a random effects model (Borenstein, Hedges, Higgins, \&
Rothstein, 2010). Effects from each of the three studies were converted in Cohen's $d$ and the associated variances were computed from the data used in the analysis sections. The meta-analysis estimated an aggregated effect of $0.76(z=6.19$, LLCI $=0.52$, ULCI $=1.00)$, which was significantly different from zero $(p<.0001)$ (see Fig. 5).

Moreover, we tested the influence of each study on the aggregated effect using a leave-one-out meta-analysis (Viechtbauer \& Cheung, 2010). This an approach implies performing a meta-analysis on each subset of the studies obtained by leaving out one study at a time. The 
results showed that the aggregated effect was significantly different from zero in each subset of experiments $(d s>0.62$, $p s<.01$, LLCI $>0.38$, ULCI $<1.09$ ). These data suggest that the difference in the acceptance index of unequal-advantageous offers between the ingroup and outgroup conditions is a robust finding.

\section{General discussion}

Our results indicated three main findings. The first finding is related to the heuristic processing of equal offers (Messick \& Schell, 1992). Consistent with the literature on the standard UG (Güth et al., 1982), regardless of the receiver's membership, equal offers were accepted more frequently and more quickly than unequal offers - both advantageous and disadvantageous. Although advantageous offers are more likely to be accepted than disadvantageous offers, the acceptance rate of equal options was higher and faster in our experiments. When facing this division option, the readiness to accept may be a result of an automatic application of the equality norm that leads to split resources following the distributional justice way (Schroeder et al., 2003) and is active when there is no reason to use a different approach. Thus, the norm of fairness (Schroeder et al., 2003) is likely to provide decisionmakers with a normative strategy and a ready-to-use rule to face the situation (Messick \& Schell, 1992) that states "accept equal proposals and reject unequal offers".

The second and central finding that emerged from our experiments is the differential impact of division option inequality on decisionmaking in relation to actor's membership. In the case of unequal-disadvantageous offers, the gain maximization principle and the fairness norm are not in conflict and both lead the decision-makers toward rejection (Messick \& Thorngate, 1967); in contrast, in the case of unequaladvantageous offers, responders face a dilemma between utility and equality. This conflict is resolved in favor of utility or equality as a function of the receiver's group membership. When inequality favors an outgroup member (i.e., in the case of unequal-advantageous offers), the participants were more prone to reject the unequal-advantageous offers than in the ingroup and control conditions, thus nullifying more often the utilities for both the proposer and receiver. In contrast, in the control condition (i.e., classic UG) where the influences of the equality and utility overlapped, the participants who were simultaneously the decision-makers and the receivers accepted advantageous offers, despite their unequality. Interestingly, in the ingroup condition, when inequality favors an ingroup member, the acceptance index increased if compared with the outgroup condition, and it was similar to the index in the control condition.

These findings, obtained by Experiment 1 and supported by Experiment 2, Experiment 3 and the final meta-analysis, may be explained in terms of intergroup bias (Brown, 2000; Hewstone et al., 2002; Tajfel \& Turner, 1979). Therefore, the rejection of unequal-advantageous offers on behalf of an outgroup member may be viewed as an attempt to avoid a benefit for the outgroup. If so, this bias may be particularly subtle because it is likely to be covered by the respect of the equality norm (i.e., the rejection of advantageous offers may be justified by their inequality).

These results are in line with recent literature (Kubota et al., 2013; Mendoza et al., 2014) on intergroup bias in economic games, showing the influence of interaction partner membership on the decision to accept or reject unequal offers. However, there are important differences between the present research and these previous studies. First, the aforementioned experiments explored the influence of the membership of the proposer who is the decision-maker interaction partner in the standard version of the UG. Differently, our research focused on the influence of the receiver membership. Second, our main result regards the propensity to accept unequal-advantageous offers rather than reject unequal-disadvantageous offers. Finally, and more importantly, we adopted a TPUG that separates the role of the responder from the utility receiver, thus enabling us to disentangle a genuine reaction toward inequality and the safeguard of self-interests.

The third relevant finding of the present research is related to the moderating role of social variables (i.e. intergroup competition and ingroup identification). From a theoretical perspective, the tendency to accept more unequal-advantageous offers on the bahalf of an ingroup member than of an outgroup member is compatible both with outgroup derogation and with ingroup favoritism. On one hand, since the ingroup might be considered as an extension of the Self (Tropp \& Wright, 2001), accepting unequal-advantageous offers on the behalf of ingroup members is likely to have the same psychological meaning of accepting advantageous offers for themselves. On the other hand, the rejection of the unequal-advantageous offers on the behalf of outgroup members can be a subtle way to reduce their utility. Therefore, with our experimental design, a tendency to favor an ingroup member accepting more unequal-advantageous offers or to derogate an outgroup member rejecting more unequal-advantageous offers could produce similar results. Results of Experiment 2 and, crucially, of Experiments 3 are more in line with the second explanation. In the third study, in fact, we found that participants who perceived a high level of competition between the two groups were prone to reject unequal-advantageous offers for an outgroup member. Such a difference in the decision-making between the two experimental condition (ingroup vs outgroup) disappeared for participants perceiving low level of intergroup antagonism. In Experiment 2 and 3, the effect of receiver's membership on advantageous offer acceptance proved to be unaffected by the level of responders' ingroup identification: this result suggests that the attachment to the one's ingroup per se without perception of intergroup competition is not likely to affect the process (Brewer, 1999). Thus, these studies provided a first attempt not only to show the phenomenon but also to explain the underlying mechanism. However, in Experiment 4, where the responder's utility was related to the receiver's gain, the acceptance rate of unequaladvantageous offers was influenced by the ingroup identification. In this last study, only highly identified participants showed rejection behavior in the case of outgroup directed unequal-advantageous offers. Therefore, when the identification was high and the ingroup was thus represented as an extension of the decision-maker's Self, the dilemma between utility and equality was solved by rejecting the payoffs that were advantageous for the outgroup members. Although in the last study it arose only for highly identified responders, the effect is particularly surprising when we consider that the rejection of unequal-advantageous offers directed to outgroup targets led to a lower payoff and no longer maximized utility for the decision-makers.

It is important to note that our manipulation implied groups created ad-hoc on the basis of a bogus personality test. This methodological choice enabled us to explore the process preventing the influence of participants' a-priori beliefs and stereotypes regarding the ingroup and the outgroup. Therefore, the effects described are likely to be weaker than those elicited by more relevant social groups such as ethnic, professional or gender categories: we expect that the individuals' motivation to favor these ingroups on which they base their identity in everyday life or to devalue the outgroups with which they may experience real competition would enhance the bias.

Furthermore, in the social context, real groups often have different power, status, roles and resources: these asymmetries shape individuals' perception of justice and fairness in distributional outcome (e.g., Mannix et al., 1995). Whereas our experiments started from the assumption that equal resources division between interaction partners is the normative benchmark to which the decision-makers contrast the proposer's division offer, in the social arena they are likely to use other fairness a-priori principles as equity or need. For example, following the equity or need rule, people could consider an unequal-advantageous offer fair when the receiver is member of a discriminated minority group; viceversa, an unequal-disadvantageous offer might be perceived as a fair option when the receiver is member of the upper social class. For these reasons, our findings should be supported by further studies that will focus on meaningful social identities and real social groups to 
generalize the results to naturalistic settings and to explore the role of the aforementioned motivational factors.

Further studies are also needed to answer questions that our work cannot investigate. For instance, another possible mechanism explaining our results is related to the influence of the membership on the interpretation of the proposer's offer. When the receiver was an ingroup member, the participant could have been prone to interpret the favorable division option as an act of generosity behaved by the proposer; in contrast, when the receiver was an outgroup member, the participant may have focused the attention on the inequality of the split. In fact, as the robust line of research on the motivated cognition highlighted (e.g. Kunda, 1990), people are likely to interpret the information to arrive at particular and desired conclusions or to justify behavioral response. Thus, the observed outcome on acceptance rate might be driven by a different intentions interpretation.

Furthermore, our experimental design does not enable the examination of vis-à-vis behavior in a situation in which participants can freely interact. In a situation in which a decision-maker and the third party receiver dynamically switch their positions, the former may be more inclined to bypass inequality aversion even for an outgroup member to trigger reciprocity that will lead the latter to do the same when deciding on his/her behalf. This implementation may produce interesting insights on how group barriers may be overridden to induce more intergroup cooperation. Another important caveat is the link between the decision-maker's and receiver's utility. As shown in Experiment 4, bonding the responder's and receiver's utility influences the decision outcome and limits the bias in some conditions (i.e., low identification). Thus, a future study could directly compare two versions of our TPUG with bounded and non-bounded utility to assess the strength of this influence.

Overall, our empirical examination may have critical implications for the public and political debate. Our findings suggest that social bonds may lead to different behaviors in terms of equality and fairness. Even with good intentions, economic agents are prone to show less equal conduct if the consequences favor and support an ingroup rather than outgroup member. This subtle process may enhance disparities that emerge between different social groups. As high-power decisionmakers in contemporary society tend to be individuals with high socioeconomic status, high status individuals could be favored if compared to low socio-economic status individuals. Therefore, knowledge of the processes that lead individuals to bypass the equality norm based on their membership may be useful to implement interventions that aim to stop detrimental behavior. This knowledge may help policy makers implement decisional processes that are structurally robust to unfair practices.

\section{Open practices}

The experiments in this article earned Open Data badge for transparent practices. Data for the experiments are available at https://osf. io $/ 4 \mathrm{q} 3 \mathrm{dc} /$.

\section{References}

Abbink, K., Brandts, J., Herrmann, B., \& Orzen, H. (2012). Parochial altruism in intergroup conflicts. Economics Letters, 117, 45-48.

Alexander, R. D. (1987). The biology of moral system. New York: Aldine de Gruyter.

Aron, A., \& Aron, E. N. (1997). Self-expansion motivation and including other in the self. In S. Duck (Ed.). Handbook of personal relationships: Theory, research and interventions. Hoboken, NJ: John Wiley \& Sons Inc.

Bernhard, H., Fischbacher, U., \& Fehr, E. (2006). Parochial altruism in humans. Nature, 442, 912-915.

Boehm, C. (1999). Hierarchy in the Forest: The evolution of egalitarian behavior. Cambridge: Harvard University Press.

Bolton, G. E. (1991). A comparative model of bargaining: Theory and evidence. The American Economic Review, 81, 1096-1136.

Bolton, G. E., \& Ockenfels, A. (2000). ERC: A theory of equity, reciprocity, and competition. The American Economic Review, 90, 166-193.

Borenstein, M., Hedges, L. V., Higgins, J. P. T., \& Rothstein, H. (2010). A basic introduction to fixed-effect and random-effects models for meta-analysis. Research Synthesis Methods, 1(2), 97-111.

Brewer, M. B. (1999). The psychology of prejudice: Ingroup love and outgroup hate? Journal of Social Issues, 55, 429-444.

Bromley, D. B. (1993). Reputation, image and impression management. Oxford: John Wiley \& Sons.

Brosnan, S. F., \& de Waal, F. B. M. (2003). Monkeys reject unequal pay. Nature, 425, 297-299.

Brosnan, S. F., Schiff, H., \& de Waal, F. B. M. (2005). Tolerance for inequity may increase with social closeness in chimpanzees. Proceedings of the Royal Society B, 272, 253-258.

Brown, R. (2000). Social identity theory: Past achievements, current problems and future challenges. European Journal of Social Psychology, 30, 745-778.

Cameron, J. (2004). A three-factor model of social identity. Self and Identity, 3, 239-262.

Cialdini, R. B., \& Goldstein, N. J. (2004). Social influence: Compliance and conformity. Annual Review of Psychology, 55, 591-621.

Civai, C. (2013). Rejecting unfairness: Emotion-driven reaction or cognitive heuristic? Frontiers in Human Neuroscience, 7, 1-3.

Civai, C., Corradi DellAcqua, C., Gamer, M., \& Rumiati, R. I. (2010). Are irrational reactions to unfairness truly emotionally-driven? Dissociated behavioural and emotional responses in the Ultimatum Game task. Cognition, 114, 89-95.

Civai, C., Crescentini, C., Rustichini, A., \& Rumiati, R. I. (2012). Equality versus selfinterest in the brain: Differential roles of anterior insula and medial prefrontal cortex. NeuroImage, 62, 102-112.

Civai, C., Rumiati, R. I., \& Rustichini, A. (2013). More equal than others: Equity norms as an integration of cognitive heuristics and contextual cues in bargaining. Acta Psychologica, 144, 12-18.

Cohen, J. (1988). Statistical power analysis for the behavioral sciences. NJ: Lawrence Earlbaum Associates.

Darwin, C. (1871). The descent of man, and selection in relation to sex. London: J. Murray.

De Dreu, C. K. W., Greer, L. L., Handgraaf, M. J. J., Shalvi, S., Van Kleef, G. A., Baas, M., , Feith, S. W. W. (2004). The neuropeptide oxytocin regulates parochial altruism in intergroup conflict among humans. Science, 328, 1408-1411.

Falk, A., \& Fischbacher, U. (2006). A theory of reciprocity. Games and Economic Behavior, 54, 293-315.

Faul, F., Erdfelder, E., Lang, A. G., \& Buchner, A. (2007). G*Power 3: A flexible statistical power analysis program for the social, behavioral, and biomedical sciences. Behavior Research Methods, 39, 175-191.

Fehr, E., Bernhard, H., \& Rockenbach, B. (2008). Egalitarianism in young children. Nature, 454, 1079-1084.

Fehr, E., \& Schmidt, K. M. (1999). A theory of fairness, competition and cooperation. The Quarterly Journal of Economics, 817-868.

Friedman, M. (1953). Essays in positive economics. Chicago.

Gaertner, S. L., Mann, J., Murrell, A., \& Dovidio, J. F. (1989). Reducing intergroup bias: The benefits of recategorization. Journal of Personality and Social Psychology, 57, 239-249.

Güth, W., Schmidt, C., \& Sutter, M. (2007). Bargaining outside the lab - a newspaper experiment of a three-person ultimatum game. The Economic Journal, 117, 449-469.

Güth, W., Schmittberger, R., \& Schwarze, B. (1982). An experimental analysis of ultimatum bargaining. Journal of Economic Behavior and Organization, 3, 367-388.

Hayes, A. F. (2013). Introduction to Mediation, Moderation, and Conditional Process Analysis: A Regression-Based Approach. New York, NY: Guilford Press.

Henrich, J., McElreath, R., Barr, A., Ensminger, J., Barrett, C., Bolyanatz, A., ... Ziker, J. (2006). Costly punischment across human societies. Science, 312, 1767-1770.

Hewstone, M., Rubin, M., \& Willis, H. (2002). Intergroup bias. Annual Review of Psychology, 53, 575-604.

Homan, A. C., Van Knippenberg, D., Van Kleef, G. A., \& De Dreu, C. K. (2007). Bridging faultlines by valuing diversity: Diversity beliefs, information elaboration, and performance in diverse work groups. Journal of Applied Psychology, 92, 1189-1199.

Kubota, J. T., Li, J., Bar-David, E., Banaji, M. R., \& Phelps, E. A. (2013). The price of racial bias: Intergroup negotiations in the ultimatum game. Psychological Science, 24, 2498-2504.

Kunda, Z. (1990). The case for motivated reasoning. Psychological Bulletin, 108(3), 480.

Mannix, E. A., Neale, M. A., \& Northcraft, G. B. (1995). Equity, equality, or need? The effects of organizational culture on the allocation of benefits and burdens. Organizational Behavior and Human Decision Processes, 63(3), 276-286.

Mendoza, S. A., Lane, S. P., \& Amodio, D. M. (2014). For members only: Ingroup punishment of fairness norm violations in the ultimatum game. Social Psychological and Personality Science, 1-9.

Messick, D. M., \& Schell, T. (1992). Evidence for an equality heuristic in social decision making. Acta Psychologica, 80, 311-323.

Messick, D. M., \& Thorngate, W. B. (1967). Relative gain maximization in experimental games. Journal of Experimental Social Psychology, 3, 85-101.

Oxfam (2015). Wealth: Having it all and wanting more.

Pickett, C. L., Silver, M. D., \& Brewer, M. B. (2002). The impact of assimilation and differentiation needs on perceived group importance and judgments of ingroup size. Personality and Social Psychology Bulletin, 28, 546-558.

Rabin, M. (1993). Incorporating fairness into game theory and economics. The American Economic Review, 83, 1281-1302.

Sanfey, A. G., Rilling, J. K., Aronson, J. A., Nystrom, L. E., \& Cohen, J. D. (2003). The neural basis of economic decision-making in the ultimatum game. Science, 300, 1755-1758.

Schroeder, D. A., Steel, J. E., Woodel, A. J., \& Bembenek, A. F. (2003). Justice within social dilemmas. Personality and Social Psychology Review, 7, 374-387.

Smith, E. R., \& Henry, S. (1996). An in-group becomes part of the self: Response time evidence. Personality and Social Psychology Bulletin, 22, 635-642. 
Tajfel, H., Billig, M. G., Bundy, R. P., \& Flament, C. (1971). Social categorization and intergroup behaviour. European Journal of Social Psychology, 1, 149-178.

Tajfel, H., \& Turner, J. (1979). An integrative theory of intergroup conflict. In W. G. Austin, \& S. Worchel (Eds.). The social psychology of intergroup relations. Brooks/Cole Publishing Company.

Tetlock, P. E., \& Manstead, A. S. (1985). Impression management versus intrapsychic explanations in social psychology: A useful dichotomy? Psychological Review, 92, 59-77.

Tropp, L. R., \& Wright, S. C. (2001). Ingroup identification as the inclusion of ingroup in the self. Personality and Social Psychology Bulletin, 27, 585-600.

Tyler, T., \& Hastie, R. (1991). The Social Consequences of Cognitive Illusions. In M. H Bazerman, R. J. Lewicki, \& B. H. Sheppard (Vol. Eds.), Research on Negotiation in Organization. 3. Research on Negotiation in Organization (pp. 69-98). Greenwich, CT:
JAI Press.

Turner, J. C., \& Reynolds, K. J. (2001). The social identity perspective in intergroup relations: Theories, themes, and controversies. In R. Brown, \& S. L. Gaertner (Eds.). Blackwell handbook of social psychology: Intergroup processes. Oxford: Blackwell Publishing.

van't Wout, M., Kahn, R. S., Sanfey, A. G., \& Aleman, A. (2006). Affective state and decision-making in the ultimatum game. Experimental Brain Research, 564-568.

Viechtbauer, W., \& Cheung, M. W. L. (2010). Outlier and influence diagnostics for metaanalysis. Research Synthesis Methods, 1, 112-125.

Warneken, F., \& Tomasello, M. (2006). Altruistic helping in human infants and young chimpanzees. Science, 311, 1301-1303.

Yamagishi, T., \& Mifune, N. (2015). Parochial altruism: Does it explain modern human group pasychology? Current Opinion in Psychology, 7, 39-43. 